\title{
Evaluation of Hydrogeology of the Lower Son Valley Based on Remote Sensing Data
}

\author{
Manas Banerjee $^{{ }^{*}}$, Debolin Bhattacharya ${ }^{1}$, Hriday Narain Singh ${ }^{1}$, Daya Shanker ${ }^{2}$ \\ ${ }^{1}$ Department of Geophysics, Banaras Hindu University, Varanasi, India \\ ${ }^{2}$ Department of Earthquake Engineering, Indian Institute of Technology Roorkee, Roorkee, India \\ E-mail:manasgp@yahoo.co.in,hridaynarain.singh@gmail.com,dayasfeq@iitr.ernet.in \\ Received July 31, 2010; revised September 2, 2010; accepted September 8, 2010
}

\begin{abstract}
Remote sensing, one of the most important reconnaissance and feature identifying tools generally applied for surface and groundwater investigation, was used for water resources mapping for the lower Son Valley in this study. The mapping was done with the help of Indian Remote Sensing (IRS) satellite imagery IRS-LISS1-B1 for January 29, 1991 obtained during the day transit time. The area under study comprises adjoining parts of Uttar Pradesh and Bihar states of India and extends over the seven districts, namely Bhojpur, Rohtas, Patna, Jahanabad, Aurangabad, Ballia and Chapra. Geology of the study area is quite complex, tectonically disturbed and shows four major cycles of depositions after erosions during last one billion years (since Cretaceous). Two lineaments mapped by GSI (Geological Survey of India) in western side of river Son in the Bhojpur district can also be identified by the satellite imagery. In the present study, apart from these lineaments, two new lineaments have been investigated, which run almost parallel to river Ganga in northwest parts of the area in Ballia district. The lineaments may play a very vital role in groundwater monitoring in the area. The detailed study of geomorphology, vegetation and geology of the Lower Son valley on the basis of photo-interpretation techniques for surface features, drainage pattern and density, and drainage texture has been carried out to determine alluvial type, permeability, tributary, etc. These studies and Darcy velocity analysis show that the prospect of water is very good for entire lower Son valley. The Bhojpur district is most prospective for groundwater exploitation.
\end{abstract}

Keywords: Lower Son Valley, Groundwater Monitoring, Satellite Imageries, Vindhyan Super Group of Kaimur Series, Lineaments, Drainage Analysis

\section{Introduction}

Remote sensing is one of the modern tools used for quick investigations of a country's natural resource potentialities with particular reference to the occurrence of the rocks, soils, water and vegetation. Remote sensing studies of aerial photographs and satellite imageries have proved to be very important in providing data on parameters that are essential in judging the water resources of a particular region. Several authors have used remote sensing for the investigation of field studies permitted the study of structures and correlated them with lineament interpretations [1-9]. Hydro-geological setting of springs and wells were investigated in the field from well logs and pumping test data. All thematic layers were integrated and analysed in a GIS. The parameters include the nature and distribution of vegetation, soil-moisture, drainage patterns and their frequency. Also the other important aspects are the nature of rock types and their structural attitudes and the geomorphologic features of the area. The geology of the area is quite complex and there are major tectonic disturbances with four major cycles of depositions and erosions (diastrophism) during last one billion years [10]. The basement is Vindhyan super group of the Kaimur series followed by erosion; then Rajpur and Mohanpur formations occur and followed by erosion. Next formation is Hanumannagar which is bare formation between two erosion unconformities [10]. The study area covers several districts: Bhojpur, Rohtas, Patna, Jahanabad, Aurangabad, Ballia and Chapra of the Uttar Pradesh. In this paper, we investigated two lineaments alongside of the river Ganga in northwest parts of 
the area in Ballia district, which may play a very vital role in groundwater monitoring in the area. A detailed analysis of geomorphology and geology of the Lower Son valley on the basis of photo-interpretation techniques for surface features, drainage pattern and density, and drainage texture has been carried out to determine alluvial type, permeability, tributary, etc. As there have been wide varieties of material exogeny with varying drainage patterns, textures and densities, the materials are found to have different hydrologic properties. The Darcy velocity analysis enab- led to find the flow pattern of ground water. Thus, we find that the water potentiality of the entire Lower Son valley is very high, and there is a very good prospect for its exploitation in future.

\section{Location of the Study Area}

\subsection{Imagery of the Study Area}

The satellite imagery used is IRS LISS $1 \mathrm{~B} 1$ (index no. 62PO22-R50), taken on $29^{\text {th }}$ January 1991 at 10:01:24 AM. The scale of the imagery is $1: 250000$ in the band -1 (Figure 1).

\subsection{Coverage of the Study Area}

The area under investigation is about $13000 \mathrm{~km}^{2}$ covering 44 administrative blocks and located between $24.5^{\circ}$ $26^{\circ} \mathrm{N}$ latitude and $83.5^{\circ}-84.8^{\circ} \mathrm{E}$ longitude (Figure 2). The area of interest is covered by the Survey of India toposheet No. 72 C \& D (1:250000) and extends over seven districts, namely Bhojpur, Rohtas, Patna, Jahanabad, Aurangabad, Ballia and Chapra.

\subsection{Climate}

The basin lies in a zone of average rainfall of $1250 \mathrm{~mm}$. About $88 \%$ of the annual precipitation occur during the four monsoon months June-September, of which $60 \%$ is recorded in only two months, July and August. During summer, the rainfall is about $3 \%$ of the total precipitation with the air temperature as high as $45^{\circ} \mathrm{C}$ and the relative humidity of the basin is $38 \%$. In winter, the minimum air temperature is $6^{\circ} \mathrm{C}$ and the relative humidity is $63 \%$. The daily mean wind speed in December is $4.2 \mathrm{~km} / \mathrm{hr}$, which rises to $8.5 \mathrm{~km} / \mathrm{hr}$ in May. The average annual wind speed is $6.5 \mathrm{~km} / \mathrm{hr}$.

\section{Methodology}

In the present study, direct visual analysis has been carried out from maps of the spatial arrangement, combinations, relationships, and changes in phenomena for the in- terpretation of geologic features, such as lineaments, alluvial types, land use pattern, geomorphologic features, etc. The use of direct and indirect indicators has been made where they were necessary. Some measurements on the imagery have also been made related to coordinates, distances, lengths, elevations, areas, and other quantitative characteristics of objects. Mapinfo has been used for the preparation of maps, particularly for drainage analysis, and to show the flow direction of ground water. The flow direction of ground water has been determined from Darcy velocity analysis.

\section{Geology of the Area}

The entire study area comprises of alluvium which is a part of Ganga basin [10]. The quality of soils indicates that the alluvium is fluvial and lacustrine origin of the Quaternary period. In Bihar, the Vindhyan occurs mainly in south Rohtas as scarps and plateaus [11]. Geological formation of the Bhojpur district forms a part of the axial belt of the Indo-Gangetic plain consisting of newer and older alluvia. The alluvial sediments consist of clay, fine to coarse-grained sand, kankar, gravel and have a maximum thickness along the present course of the Ganga. The micaceous sands brought and deposited by the river Ganga is gray in colour and rich in magnesium minerals (such as serpentine, olivine, talc) and occupy topmost horizon along the river course for a few kilometers. This layer belongs to the newer alluvium consisting of clay, kankar, fine to coarse grained sand, gravel and pebble at depth. The lower Son Valley is formed by the torrent of the Vindhyan. Therefore, the geological features, drainage patterns and their frequencies of occurrence in the Vindhyan region were mainly responsible for the hydro-geological developments of the area [1].

\subsection{Delineation of Lineaments}

In photo-geology, the lineaments are defined as linear alignment of features with different shades on photos and imageries. These could be clearly demarcated on the satellite imagery IRS-LISS-1-B1 as a distinct tonal variation in gray shades along two parallel lines in the northern fringe of the lower Son valley in the Bhojpur district along lines A-A and B-B as shown in Figures $\mathbf{1}$ and 2. Two new lineaments have been inferred on the basis of variation in gray tones through soil characteristics, vegetations and drainage patterns in the north-west corner of the area in the Ballia district along lines C-C and D-D (Figures 1 and 2). These are clearly demarcated in the imagery (Figure 1) as the soil characteristics, vegetationns and drainage patterns are quite different on either sides of the lines C-C and D-D. However, the presence of 
these new lineaments must be examined by other techniques in the future.

\section{Geomorphological Analysis}

The photo-geo-morphological features of the area around the lower Son valley are highlighted in the following paragraphs. These are related to topography and drainage aspects.

\subsection{Topography}

The Son valley mainly consists of alluvial deposits of the rivers Son and Ganga. Northern part of the lower Son valley is composed of the finer alluvium deposits derived from the river Ganga. It is clear that the fan shaped lower

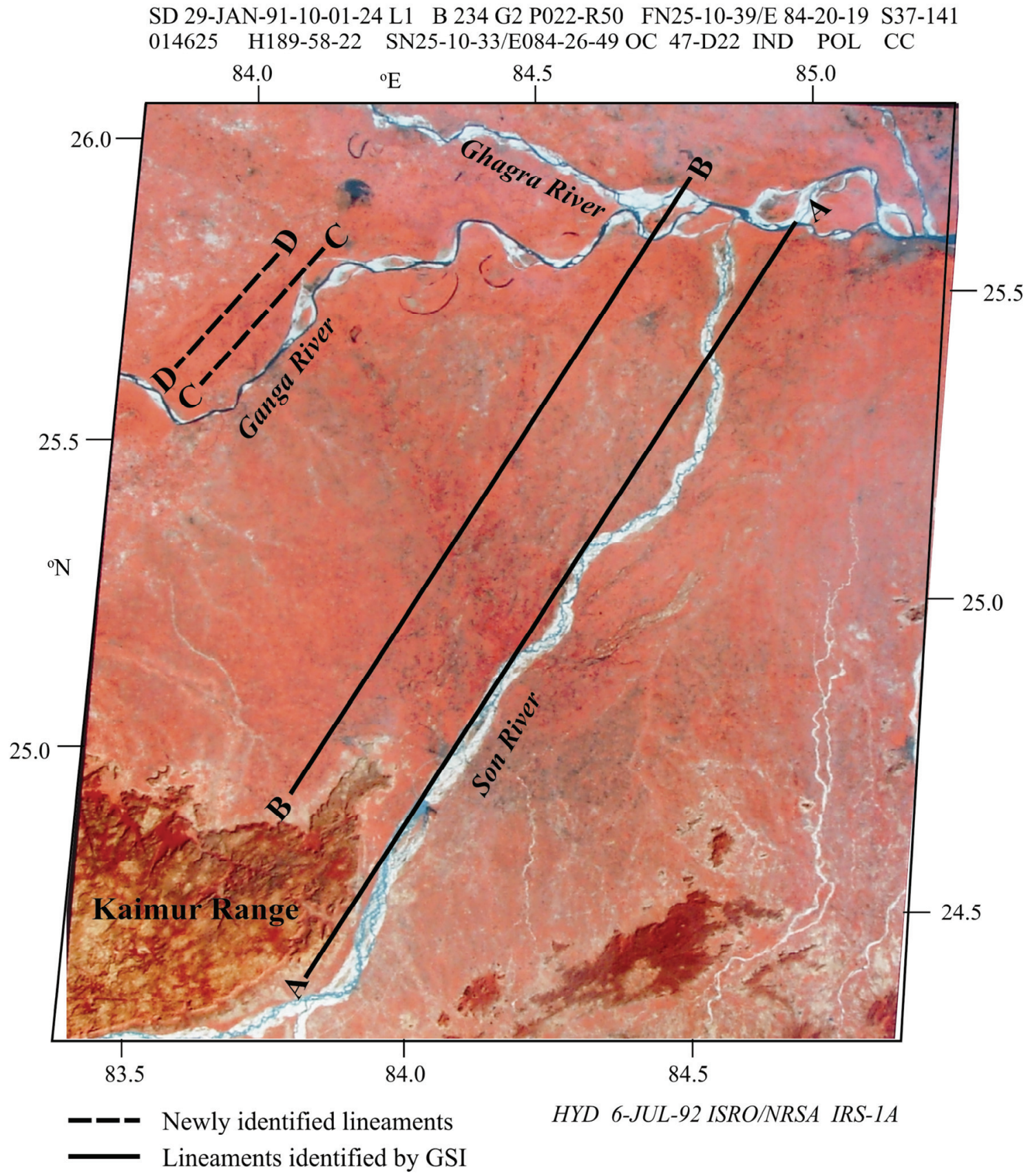

Figure 1. Satellite imagery of the Lower Son valley showing major rivers and other surface features. Two lineaments delineated by GSI (A-A and B-B) and two lineaments mapped in the present study (C-C and D-D) are also indicated. 


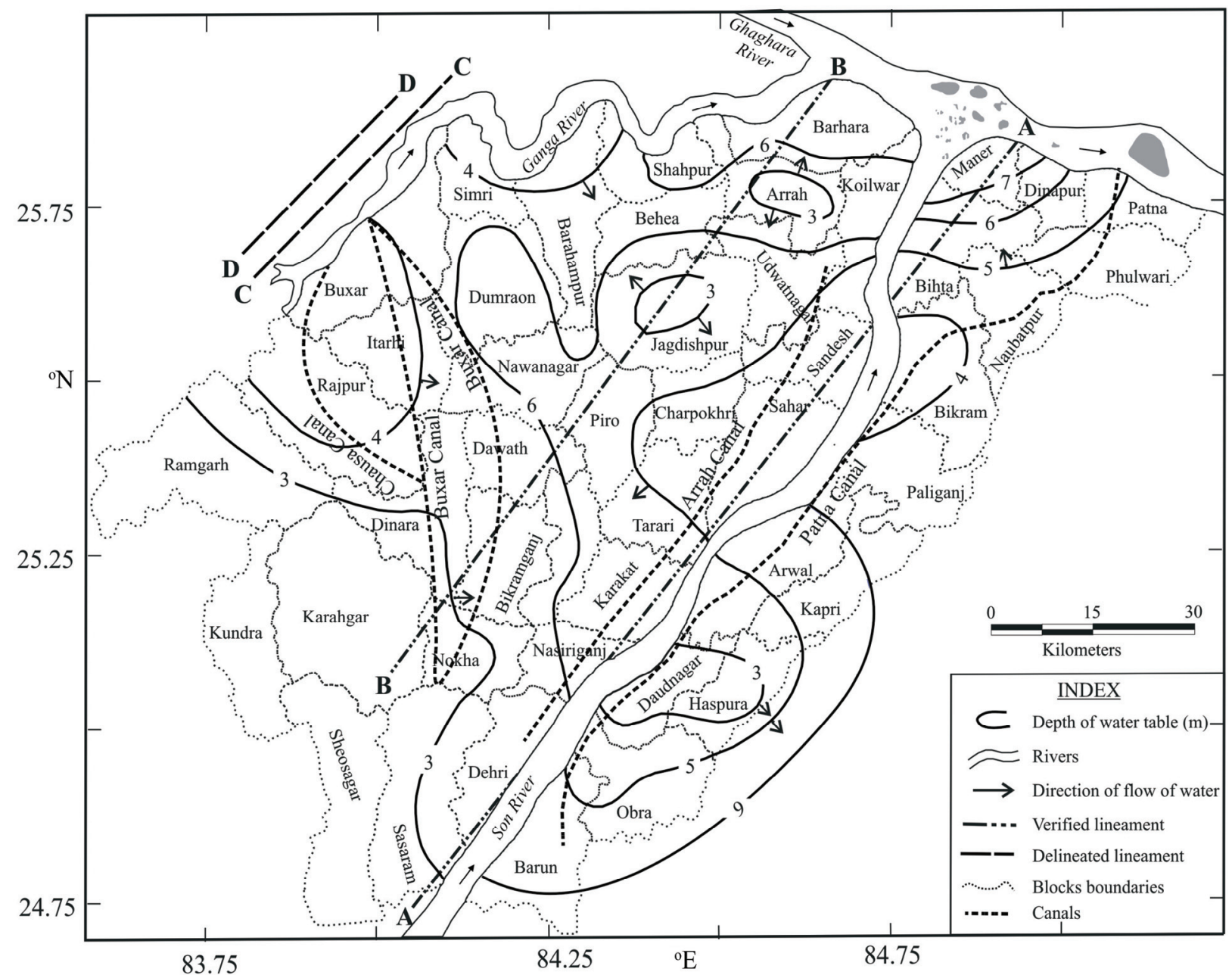

Figure 2. The location map of the study area showing administrative boundaries of districts and blocks with major rivers and major lineaments delineated by Geological Survey of India (A-A and B-B) and two lineaments mapped in the present study (C-C and D-D). The pattern of groundwater movement in the Lower Son valley during January 1991 (by courtesy CGWB report) is also indicated.

Son valley is practically uniform, which is sloping towards north-west, north and north-east directions. The average ground slope of this area is $0.5 \mathrm{~m} / \mathrm{km}$ (1 in 2000) such that all the tributaries of Ganga flow towards north in the central region. In the eastern part of the lower Son valley, the rivers Son and Punpun flow almost parallel which was mainly ravaged by the river Son and hence this portion has many depressions.

\subsection{Drainage Analysis}

Drainage pattern is the special arrangement of streams, which reflects the characteristic features of the terrain with a geometric regularity and helps in understanding the fluvial system of the area. The following features were inferred from the drainage density map (Figure 3).

1) In Ballia district, there is rapid fall of the drainage density about a line in a manner that on one side of this line, the drainage pattern is dendritic with medium texture (Figure 3), while on the other side, (i.e., in the northern side of the river Ganga), the drainage density is poorly developed that reflects the existence of lineaments $\left(24.75^{\circ} \mathrm{N}\right.$ and $\left.84^{\circ} \mathrm{E}\right)$. The drainage pattern in this region is medium textured, which implies that the soil contains mixture of materials of low permeability $[12,13]$.

2) Rapid fall of drainage density was also observed between Nokha and Sasaram which shows variation in permeability between these two regions. The drainage pattern is medium textured reflecting that the soil contains mixture of fine and coarse materials.

3) A medium textured drainage pattern is observed in Jagdishpur block; whereas medium textured dendritic to subdendritic drainage patterns were observed in Piro, Bihata and Danapur blocks. These patterns indicate a mod- 
erate surface runoff because of the presence of an impervious lower stratum of soil having moderate permeability.

4) A fine textured rectangular drainage pattern is observed over soil having low permeability at Nawanagar block, which is formed by joining of tributaries with the main stream at right angles. It indicates the higher probability of occurrence of slate, schist, gneiss and sandstone with high level of surface runoff.

5) In Aurangabad district, fine dendritic drainage pattern was basically observed, which indicates homogeneous and uniform soil with landforms of soft sedimentary rocks.

6) At Dinara, a coarse textured drainage pattern was mainly observed. This pattern is an indicator of a first order stream [14]. The hydrological parameters, such as permeability, transmissivity and Darcy velocity are all very large.

7) A rapid decrease of drainage density was observed between Naubatpur and Bikram blocks. In Charpokhri block, fine to coarse textured drainage pattern was observed, which indicates the variation in permeability of soil and surface runoff from place to place.

8) In Patna, a fine textured drainage pattern was observed, which indicates the high level of surface runoff and the soil with low permeability.

\section{Groundwater Investigation}

\subsection{Landuse Pattern and Agriculture}

The satellite imagery indicates that part of the Bhojpur district and more than $60 \%$ of the area of Rohtas district are croplands including some barren lands and gullied regions. It is investigated that more than $70 \%$ of the land in the lower Son valley is under paddy cultivation during monsoon period whereas the intensity of Rabi crop is limited to $50 \%$ only. The principal crops grown in the Bhojpur district are autumn paddy, winter paddy, summer paddy, wheat and autumn maize, summer maize, gram, sugarcane, potato, fruits and vegetables. The dry land of Baraha, Semri, Barahampur, Sahpur and Koelwar blocks is generally flooded every year and is called single cropped area where only Rabi crops are grown. The main Rabi crops in these areas are wheat and gram $[11,12,15,16]$.

\subsection{Use of Indicators for Groundwater Investigation on Remote-Sensing Data Products}

The various surface features observed on remote sensing data products are grouped into two categories:

1) First order or direct indicators, e.g., the features associated with recharge zones (rivers, canals, lakes, pon- ds), and discharge zones (effluent seepages, springs), soil moisture, anomalous vegetation.

2) Second order or indirect indicators, e.g., the topographic features and the general surface gradients, types of rocks (soft and hard rocks), regional structural features such as lineaments, types of soil, drainage density and fracture systems in hard rock areas [17].

\subsection{Interpretation of the Satellite Imagery}

The visual interpretation based on satellite imagery [8] regarding the groundwater condition of the area under investigation is summarized below:In the Bhojpur district, 25 tributaries are located. The Arrah and Buxar canals are running through the Bhojpur district and feeding the regime with imported water (Figure 2). The large number of recharge zones such as ponds and palaeo-channels are located (Toposheet $72 \mathrm{C} \& 72 \mathrm{D}$ ). These features indicate that the surface water condition is good and it is further verified from the well data, which shows that the depth to the water is in the range of 3 to $4 \mathrm{~m}$ below ground surface. In this district, anomalous vegetation is located in the Jagdishpur block. The above features reveal that the groundwater potential as well as surface water conditions are very good in the Bhojpur district.

A deep forest belt is located in the Sasaram block which lies on sandstone plateau of the Kaimur range with good porosity and permeability. The well data indicates that there is good prospect of groundwater in Sasaram. The Buxar block is situated very close to south of the river Ganga. The surface water bodies are the major source for recharge of groundwater in this block, with scanty vegetation. A large number of drainage pattern (Figure 3) indicates that porosity of the soil is good with low permeability and the well data gives depth to the water table as $4 \mathrm{~m}$. It can be inferred that as yield is poor in this block the groundwater prospect is not good. It is seen on the imagery that the Patna canal is running from Aurangabad to Patna through Jahanabad which is again feeding the subsurface water as well (Figures 2). Therefore, the groundwater condition should be quite good for the Bhojpur district.

The satellite imagery indicates that there are a few tributaries in the Rohtas district [14] with the total recharge area being less than that of the Bhojpur district. The imagery indicates that the regions of Ganga and Ghagra are very less vegetated while Ballia and Chapra are almost barren. Ground truth suggests that the region comes under the heavy influence of flood during monsoon period. Some water bodies can be seen on the imagery which may be due to heavy rainfall. Also very fine-textured drainage pattern is observed which indicates low permeability and high level of surface runoff. The groundwater 


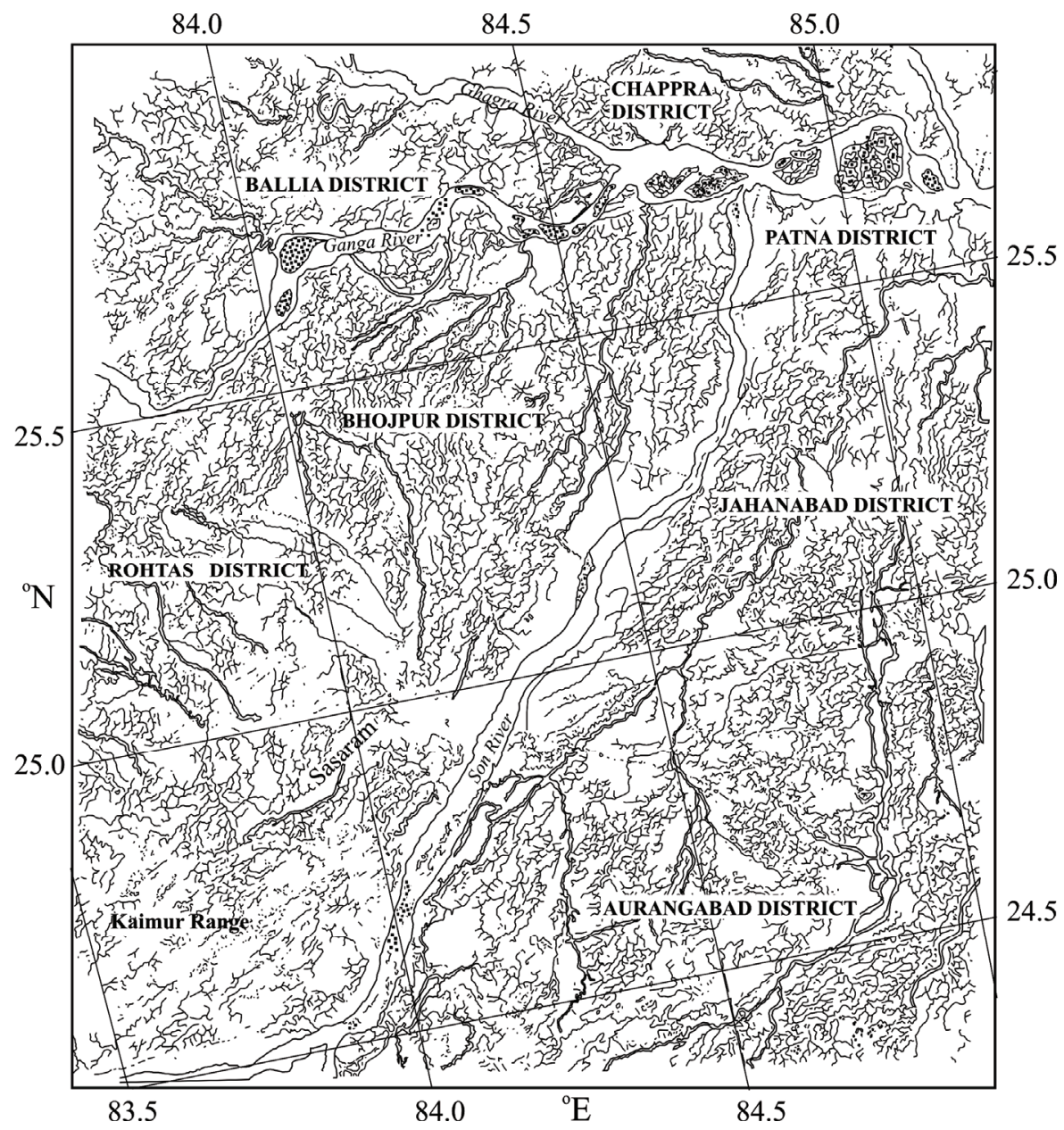

Figure 3. Drainage pattern of the study area as interpreted from the Survey of India toposheets (72 C \& 72 D) on 1: 250000 scale.

condition in both Ballia and Chapra is inferred to be poor. The surface water condition of the Rohtas district is not very good due to poor coverage of vegetation and the presence of a large number of drainage patterns over the hard rock areas. The Arrah block is situated near the river Ganga and many rivulets and tributaries are located. Large number of drainage patterns including linear pattern are observed. The well data confirms that the depth to water is about $3 \mathrm{~m}$ below the ground surface (Figure 4). Therefore, it is inferred that the groundwater condition of Arrah and its adjoining area is very good. It is quite distinct on the imagery that the Patna district is enclosed by the rivers Ganga and Son. The area is having vegetations of cultivated land, many tributaries, rivulets and canals which could be identified on the imagery (Figure 1). The large number of drainage is observed (Figure 3) in which the general ground level is $250 \mathrm{~m}$ above mean sea level. The water table depth is in the range of 4 to 7 $\mathrm{m}$. These facts indicate that there is a very good hydrogeological condition prevailing in the region.
It is apparent from the imagery (Figure 1) that the Jahanabad district is highly vegetated through which the Patna canal is running (Figure 2). A large number of tributaries and rivulets are observed. The Punpun River is flowing through this district. The presence of dendritic drainage pattern indicates poor permeability of the soil having large surface runoff. The well data gives the depth to water as 5 to $9 \mathrm{~m}$. Therefore, it may be inferred that the groundwater condition in the Jahanabad district is moderate to good. Aurangabad is in the south of the Jahanabad which is highly vegetated with deep forest belts at places. The topographic elevations mostly range from 250 to $1000 \mathrm{~m}$ in this district with many rivulets but fewer tributaries (Figure 3). The dendritic drainage pattern is found to be very common with fine to medium textures (Figure 3), which indicates that the permeability of the soil to be highly variable. The well data confirms that the water table depth is in the range of 3 to $9 \mathrm{~m}$ (Figure 4). These hydrological parameters indicate that there is frequent occurrence of groundwater in Auran- 
gabad and the yield is high.

\subsection{Qualitative Analysis of Darcy Velocity of the Lower Son Valley}

The data for groundwater levels during January 1991, when the imagery was taken are presented in the Table 1, and the corresponding map of the groundwater level contours is given in Figure 2. Figure 4 shows the histograms for block wise depths of the water table of the Lower Son valley.

The average depth of water table in Sasaram, Dinara and Nokha is $3 \mathrm{~m}$; whereas that in Nasiriganj, Pawath, Dumraon, Nawanagar, Behea and Udwantnagar is $7 \mathrm{~m}$. From the study of Darcy velocity, which is expressed as: $V=(-K / a) *(d h / d l)$; where $V$ is the Darcy velocity, $K$, the hydraulic conductivity, $\boldsymbol{d} \boldsymbol{h}$, the fall in head, $\boldsymbol{d l}$, the flow path length and $\boldsymbol{a}$, the effective porosity, it is found that the fall in head takes place from west to east (Figure 2). It is clear from the drainage map that the permeability (or hydraulic conductivity) across the boundary between the Rohtas and Bhojpur district is very large and the fall in head across this boundary is quite appreciable. So the Darcy equation provides, qualitatively, the velocity as very high and the movement of groundwater takes place from the Rohtas district to the Bhojpur district. Furthermore, the fall in head takes place from Jagdispur to Behea, Barhampur, Nawanagar, Piro, Charpokhri and Udwantnagar, which indicates that the groundwater movement is from north of Bhojpur district to south-east (Figure 2) with the areas like Behea, Nawanagar, Dawath, Bikramganj and Nasiriganj having high water saturation zones. In Patna district, the fall in head takes place from south to north, i.e., from Bikram to Maner. Since the drainage analysis of this region indicates that the permeability is poor with low Darcy velocity in comparison to that across the Rohtas-Bhojpur boundary. In Aurangabad district, the fall in head takes place from Daudnagar to Barun. As the permeability of the soil in this district is variable, the Darcy velocity also varies from Daudnagar to Barun.

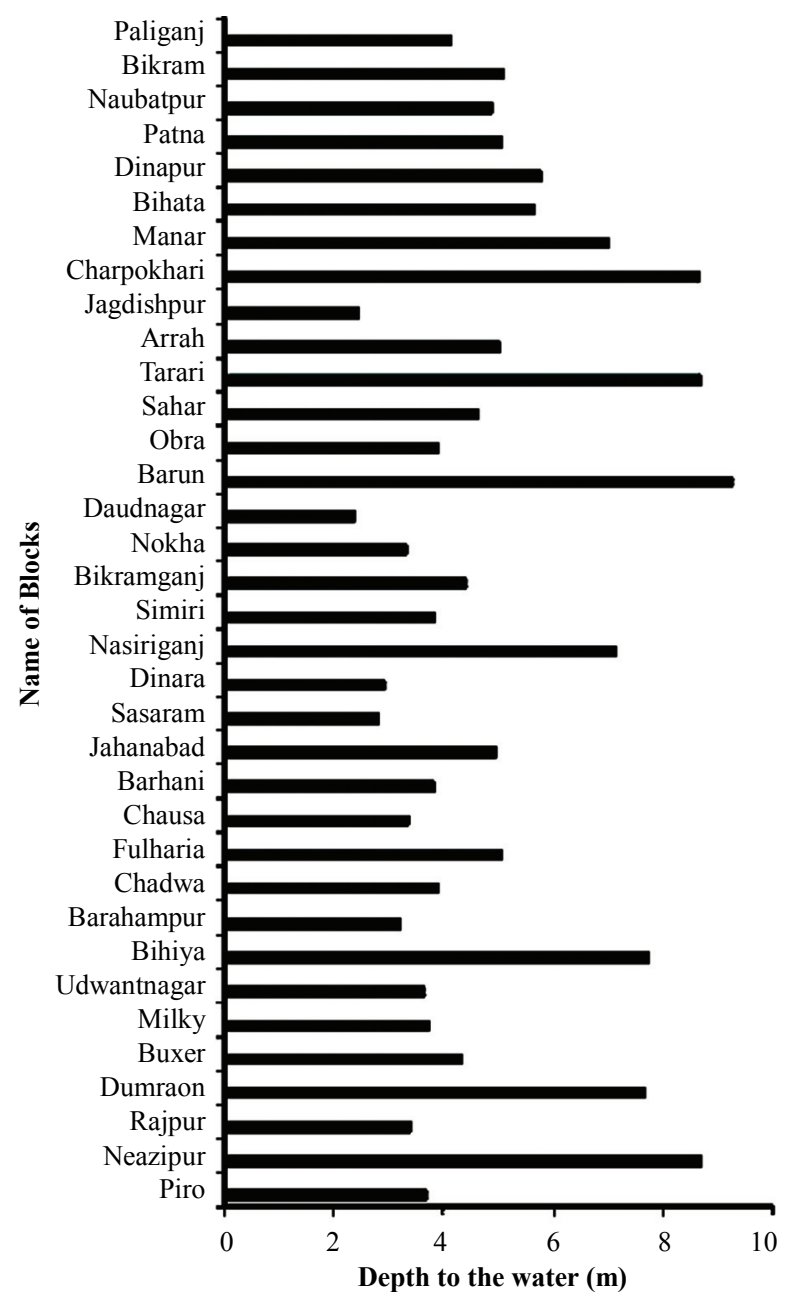

Figure 4. Histograms showing the block wise depths of the water table of the Lower Son valley.

Table 1. Block wise water table depths of Lower Son Valley.

\begin{tabular}{|c|c|c|c|c|c|c|c|}
\hline Block & $\begin{array}{c}\text { Depth to Water } \\
\text { Table }(\mathrm{m})\end{array}$ & Block & $\begin{array}{c}\text { Depth to Water } \\
\text { Table }(\mathrm{m})\end{array}$ & Block & $\begin{array}{c}\text { Depth to Water } \\
\text { Table }(\mathrm{m})\end{array}$ & Block & $\begin{array}{c}\text { Depth to Water } \\
\text { Table }(\mathrm{m})\end{array}$ \\
\hline Piro & 3.69 & Chadwa & 3.92 & Bikramganj & 4.41 & Charpokhri & 8.67 \\
\hline Neazipur & 8.68 & Fulharia & 5.06 & Nokha & 3.34 & Manar & 7.02 \\
\hline Rajpur & 3.42 & Chausa & 3.36 & Daudnagar & 2.38 & Bihta & 5.66 \\
\hline Dumraon & 7.67 & Barhani & 3.85 & Barun & 9.29 & Dinapur & 5.79 \\
\hline Buxer & 4.36 & Jahanabad & 4.98 & Obra & 3.91 & Patna & 5.09 \\
\hline Milky & 3.74 & Sasaram & 2.84 & Sahar & 4.64 & Naubatpur & 4.88 \\
\hline Udwantnagar & 3.65 & Dinara & 2.92 & Tarari & 8.71 & Bikram & 5.12 \\
\hline Bihiya & 7.77 & Nasiriganj & 7.12 & Arrah & 5.02 & Paliganj & 4.12 \\
\hline Barhampur & 3.24 & Simiri & 3.85 & Jagdishpur & 2.48 & & \\
\hline
\end{tabular}




\section{Conclusions}

Advantages of remote sensing technique and its ability to give multi-spectral, multi-spatial, multi-temporal data he$\mathrm{lp}$ a great deal in accelerating and expanding its boundaries for the application in the water resources field. The greatest advantage of using remote sensing data for hydrological investigation and monitoring is the ability to generate information on spatial and temporal domain which is crucial for successful analysis, prediction and validation. The attempt to study the satellite imagery IRS-LISS1-B1 (index no. 62PO22-R50) helped in locating the existing two parallel lineaments trending north-east in the Bhojpur district. Two new lineaments were identified in the Ballia district. The analyses of drainage, vegetation and geomorphology supported by groundwater indicators helped to infer that the water potentiality of the entire Son valley is high which corroborate well with the monitoring results of groundwater by [15]. The analysis of Darcy velocity has provided the direction and the nature of movement of ground water which may help to put wells at desired location. Among all the districts of the Lower Son valley, the Bhojpur district is having the highest water bearing potentiality.

\section{Acknowledgements}

We express our indebtness to Prof. V. P. Singh of the Department of Geophysics, and Prof. K. N. P. Raju of Department of Geography, Banaras Hindu University, Varanasi for extending facilities in their respective departments. One of the Authors (D. Shanker) is thankful to Prof \& Head Department of Earthquake Engineering, IIT Roorkee for providing excellent internet facilities and necessary assistance.

\section{References}

[1] F. Ahmad, "Geology of the Vindhyan System in the Eastern Part of Son Valley," Records GSI, Vol. 96, No. 2, 1971, pp. 1-41.

[2] S. A. Drury and S. M. Berhe, "Accretion Tectonics in Northern Eritrea Revealed by Remotely Sensed Imagery," Geological Magazine, Vol. 130, No. 2, 1993, pp. 170-190.

[3] W. Ghebreab, "An Outline of Major Pan-African Lithologic Assemblages and Shear Zones in Eritrea: Implications for Mineral Exploration," Australian Financial
Review, Vol. 3, No. 3-4, 1996, pp. 355-366.

[4] M. J. McFarlane, "Groundwater Movement and Water Chemistry Associated with Weathering Profiles of the African Surface in Malawi," In: E. P. Wright and W. G. Burgess, Eds., Hydrogeology of Crystalline Basement Aquifers in Africa, Geological Society, Special Publications, London, Vol. 66, 1992, pp. 131-154.

[5] M. G. S. D. Nilantha and V. Hari Prassad, "Groundwater Recharge Estimation Using Remote Sensing and Geographic Information System," Sri Lankan Journal of GeoInformatics, Vol. 1, 2004, pp. 44-55.

[6] A. K. Saraf and P. R. Choudhury, "Integrated Remote Sensing and GIS for Groundwater Exploration and Identification of Artificial Recharge Sites," International Journal of Remote Sensing, Vol. 19, No. 10, 1998, pp. 1825-1841.

[7] S. Solomon and F. Quiel, "Integration of Remote Sensing and GIS for Groundwater Assessment in Eritrea," In: T. Benes, Ed., Proceedings of the European Association of Remote Sensing Laboratories Conference, Ghent, 2003, pp. 633-640.

[8] S. Solomon, "Groundwater Study Using Remote Sensing and Geographic Information Systems (GIS) in the Central Highlands of Eritrea," Journal of Hydrogeology, Vol. 14, No. 6, 2006, pp. 1029-1041.

[9] R. Taylor and K. Howard, "A Tectono-Geomorphic Model of the Hydrogeology of Deeply Weathered Crystalline Rock: Evidence from Uganda," Hydrogeology Journal, Vol. 8, No. 3, 2000, pp. 279-294.

[10] G. S. I., "Report: The Miscellaneous Publication No. 63," 1999.

[11] WAPCOS, "Son Canal Modernization Project (Feasibility Report)," Vol. 1 \& 2, 1988.

[12] D. Bhattacharya, M.Sc. Dissertation, Banaras Hindu University, Varanasi, 1999, pp. 1-67.

[13] V. C. Leuder and C. F. Miller, "Photogeology," McGrawHill, London, New York, 1961.

[14] R. P. Singh, "Groundwater Management Strategies, Rohtas District, Bihar, India," Bulletin of Engineering Geology and the Environment, Vol. 63, No. 3, 2004, pp. 247-253.

[15] CGWB, "The Technical Report: Groundwater Statistics and Monitoring of Groundwater in Bihar," Series D, Vol. 96, No. 48, 1986.

[16] S. K. Nag, "Morphometric Analysis Using Remote Sensing Techniques in the Chakh Sub-Basin, Purulia District, West Bengal," Journal of the Indian Society of Remote Sensing, Vol. 26, No. 1-2, 1998, pp. 69-76.

[17] R. P. Gupta, "Remote Sensing in Geology," Springer-Verlag, New York, 1991, pp. 245-289. 